\title{
Iniciação Científica Júnior: desafios à materialização de um círculo virtuoso
}

\author{
Adriano de Oliveira ${ }^{a}$ \\ Lucídio Bianchetti ${ }^{b}$
}

\section{Resumo}

Este artigo tem por finalidade analisar a trajetória da institucionalização da Iniciação Científica e da Iniciação Científica Júnior no país e, particularmente, na Universidade Federal de Santa Catarina. Para isso, metodologicamente, realizamos a análise documental de leis, indicadores e relatórios do $\mathrm{CNPq}$ e da UFSC. As razões para a política de aproximação entre a Educação Superior e a Educação Básica estão na melhoria dos níveis de permanência e no sucesso dos estudantes; no desenvolvimento do gosto pela ciência. Na Instituição onde foi realizada a pesquisa a não utilização de todas as bolsas do Programa Institucional de Iniciação Científica do Ensino Médio, como parte desta modalidade de Iniciação Cientifica, aponta a tendência de refluxo do Programa.

Palavras-chave: ICJ/Pibic-EM. Política científica e educacional. Aproximação escola-universidade.

\section{Introdução: da temática e do locus da pesquisa}

Neste artigo, oriundo de pesquisa de doutorado, abordamos o processo histórico de constituição da Iniciação Científica (IC) e da Iniciação Científica Júnior (ICJ) ${ }^{1}$ no país e na Universidade Federal de Santa Catarina (UFSC). Analisamos os indicadores e a trajetória da IC tradicional à ICJ, a convergência das políticas de fomento à formação de professores/pesquisadores do Conselho Nacional de Desenvolvimento Científico e Tecnológico (CNPq) e da Coordenação de Aperfeiçoamento de Pessoal de Nível Superior (Capes), direcionadas à Educação Básica (EB) e à implementação e ao percurso do Programa Institucional de Bolsas de Iniciação Científica do Ensino Médio (Pibic-EM) na UFSC. Para

\footnotetext{
1 Financiamento do CNPq. Três programas compõem a ICJ: o Programa Institucional de Bolsas de Iniciação Científica para o Ensino Médio (Pibic-EM); o Programa de Iniciação Científica Júnior (IC-Jr/FAPs); o Programa de Iniciação Científica da Olimpíada Brasileira de Matemática das Escolas Públicas (PIC/Obmep).

a Universidade Federal de Santa Catarina - UFSC. Florianópolis, Santa Catarina, Brasil.

b Universidade Federal de Santa Catarina - UFSC. Florianópolis, Santa Catarina, Brasil.
} 
isso, realizamos a análise documental de leis, pareceres, decretos, indicadores de fomento e relatórios do CNPq e da Instituição de Ensino Superior (IES) onde foi realizada a pesquisa. Em relação à convergência desses dois principais órgãos de fomento à pesquisa do país na formação inicial de pesquisadores e professores e na indução da aproximação entre a Educação Superior (ES) e a EB, adiantamos que as razões para isso estão: na melhoria dos níveis de permanência e no sucesso dos alunos da escola pública; no desenvolvimento do gosto pela ciência; na identificação precoce de novos talentos para a área científica e na redução do Tempo Médio de Titulação (TMT) de mestres e doutores. Na UFSC, a não utilização de todas as bolsas do Pibic-EM aponta a tendência de refluxo ou, no limite, até a extinção do Programa.

Em termos especificamente do campo de pesquisa empírica, esta foi realizada em quatro dos cinco campi $^{2}$ da UFSC, localizados na cidade de Florianópolis (campus central), Araranguá, Curitibanos e Joinville. No período de 2010 a 2015 foram concedidas 262 bolsas do Pibic-EM, sob a responsabilidade da Pró-Reitoria de Pesquisa - Propesq (PROPESQ/UFSC) desta IES, para 15 escolas públicas. A pesquisa abrangeu dez destas 15 escolas, sendo: duas federais, sete estaduais e uma municipal. Nesses campi e nessas escolas, realizamos 46 entrevistas semiestruturadas com bolsistas, orientadores da UFSC, coorientadores/professores da escola e coordenadores do Programa vinculados a IES. Nesse texto, contudo, as entrevistas não são foco de análise.

Aqui consideramos ser necessário fazer um detour, uma vez que partimos do pressuposto de que, para compreendermos o objeto em análise, o Pibic-EM, necessitamos resgatar o processo histórico de constituição das políticas públicas de formação de pesquisadores no país, implicando abordar as decisões a respeito das bolsas e dos financiamentos à pesquisa por parte dos diferentes Governos que assumiram o comando do país no período entre 1951 e 2015 . Entendemos que esta política particular do Pibic-EM somente pode ser compreendida e justificada se, na perspectiva da totalidade histórica, a inserirmos no plano mais geral daquilo que se processou, no tocante a bolsas e demais financiamentos, por parte dos órgãos de fomento e avaliação nessas últimas seis décadas.

Assim, baseando-nos em Schwarcz e Starling (2015), consideramos ser necessário, em relação a IC e a ICJ, "puxar o fio do começo dessa história", para entender como o Programa é "produtor de códigos, costumes e hábitos" (p. 51). Nessa perspectiva passaremos agora a abordar a política pública de iniciação e fomento

Atualmente a UFSC conta com quatro campi. O campus de Blumenau não estava constituído no período da pesquisa. 
à pesquisa, desde a criação do CNPq e da Capes, para, em subitem posterior, tratar da especificidade da IC e do Pibic-EM na UFSC.

Nesse contexto, a preocupação com a IC não é nova no Brasil. Porém, como ocorreu com outras decisões e implementações históricas, pioneiras, relacionadas à educação no país, em termos de políticas públicas, o começo foi "por cima", isto é, pela educação superior ${ }^{3}$. Este movimento pode ser observado também em relação ao Pibic, com a IC, em geral, e, particularmente, com a ICJ, cujo programa objetiva conceder bolsas aos alunos da EB. Contudo, antes de entrar na especificidade da nossa investigação, relacionada ao ICJ, historicizamos alguns passos, movimentos e decisões anteriores em torno da IC e do Pibic na ES.

\section{Da iniciação científica "tradicional" à ICJ}

Por meio de programas institucionais, desde sua criação em 1951, o CNPq concede bolsas de IC. A IC foi institucionalizada com a finalidade de possibilitar a formação inicial de graduandos no exercício da investigação, incentivando a pesquisa sob a orientação de investigadores, sendo considerado um "programa original, desconhecendo-se forma similar em outros países" (MARCUSCHI, 1996, p. 6). Esse era o principal meio de seleção de jovens pesquisadores que consolidariam sua formação, desenvolvendo investigações nos Institutos de Pesquisa ${ }^{4}$ e nas poucas universidades existentes. A razão da maioria das bolsas serem de IC é que não se contava ainda com programas de pós-graduação consolidados no país.

Ao procurarmos dados a respeito da IC, constatamos que, no período de 1951 a 1963, o CNPq não os apresenta, especificamente, sobre o número de bolsas de IC concedidas, contabilizando todas as bolsas como formação no país. Assim, no Governo Vargas (1951-1954) houve, logo no segundo ano, um aumento de 93\% no número de bolsas no país. No entanto, em 1953 constata-se uma queda de $20 \%$, em relação ao ano anterior. Posteriormente, com a crise política gerada pelo suicídio de Vargas e expressa também nos Governos de curta duração de

\footnotetext{
Por mais que esta situação seja de domínio público, nunca é demais ressaltar que a educação brasileira, por centenas de anos, esteve nas mãos de congregações, como os jesuítas, franciscanos, beneditinos, carmelitas, oratorianos, mercedários e capuchinhos, que atuaram de forma dispersa e descontínua, sem o apoio oficial. Nesse contexto, no entanto, foram os jesuítas que atuaram de forma mais orgânica e exerceram o monopólio da educação nos dois primeiros séculos da colonização. Até a vinda da família real portuguesa para o Brasil, o que se fazia em termos de educação pendia mais para missão do que para educação/instrução pública. O descaso com a EB e a proibição de que na Colônia se implementasse a ES faziam com que apenas alguns pudessem atravessar o mar e realizar seus estudos em universidades europeias. É com a chegada da família real, 1808, que são criados os primeiros cursos superiores e passam a ser formalizadas e implementadas normatizações para a educação fundamental e média, predominando a perspectiva do descompromisso do poder central com esta responsabilidade. Para um detalhamento deste histórico, ver, entre outros, Saviani (2014).

4 Weber (2011) enfatiza a questão de que a pesquisa, no Brasil, antes de ser desenvolvida nas universidades - especialmente devido à inexistência destas - era prática comum nos Institutos de Pesquisa.
} 
Café Filho (1954-1955) e Nereu Ramos (1955-1956), constatamos diminuição anual de $1 \%$ no número de bolsas em 1955 e 1956, respectivamente (Cf. Tabela 1). Com a posse de Juscelino Kubitscheck (1956-1961) e sua política, de caráter desenvolvimentista, houve um aumento no número de bolsas nos três primeiros anos e um refluxo nos dois últimos anos. Numericamente esse processo se traduz pelos seguintes percentuais ${ }^{5}$ : a) nos três primeiros anos de Governo, um aumento respectivamente de $123 \%, 1 \%$ e $9 \%$; b) nos dois últimos anos uma queda de 2\% ao ano. No Governo Jânio Quadros (1961) e João Goulart (1961-1964) houve ampliação no número de bolsas, em percentuais de $11 \%$ em 1961 e de 17\% em 1962. Em resumo, nos primeiros 12 anos de criação do CNPq houve uma instabilidade nos investimentos em bolsas no país, em razão do início de uma política de Estado articulada para a área da Ciência e Tecnologia (C\&T), paralelamente à instabilidade política, característica daquele período.

Tabela 1. Evolução do número e percentual de bolsas de formação no país, 1951-1962.

\begin{tabular}{lcc}
\hline Ano & Número & $\%$ \\
\hline 1951 & 75 & \\
1952 & 145 & 93 \\
1953 & 116 & -20 \\
1954 & 115 & -1 \\
1955 & 114 & -1 \\
1956 & 254 & 123 \\
1957 & 256 & 1 \\
1958 & 280 & 9 \\
1959 & 274 & -2 \\
1960 & 269 & -2 \\
1961 & 299 & 11 \\
1962 & 349 & 17 \\
TOTAL & 2.546 & \\
\hline
\end{tabular}

Fonte: Elaborado pelos autores (2017) ${ }^{6}$.

5 Este movimento de forte investimento inicial seguido de diminuição e até decréscimo orçamentário, no nível micro, da distribuição de bolsas de formação no país, pode ser observado também em outras frentes do Plano de Metas de JK, excetuando-se algumas áreas como exemplarmente foi o caso da construção de Brasília. O forte endividamento e dependência externa do Brasil em relação a ouros países do eixo dinâmico do capital foi determinante na necessidade de priorização de áreas ou frentes de investimentos (SCHWARCZ; STARLING, 2015).

6 As tabelas 1, 2, 3, 4, 5 e 6 e o gráfico 1 foram elaborados a partir de informações do site http://centrodememoria. cnpq.br/Fombols.html, em 2017. 
Nos três primeiros anos do Governo Militar (1964-1985), as bolsas de IC tiveram uma trajetória de crescimento, em relação ao último ano do Governo João Goulart (1961-1964), porém, após 1967, ocorreram oscilações, como podemos observar na Tabela 2 apresentada mais adiante. A partir de 1969 o número de bolsas de formação e qualificação passou para 500, ultrapassando as 373 de IC (representando $57 \%$ e $43 \%$ do total respectivamente). Esse quadro de crescimento de ambas as modalidades e de priorização da Pós-Graduação (PG) prosseguiu até o final desse governo, que concebia a C\&T como fator de desenvolvimento, com 1.321 (crescimento de 437\%) bolsas de IC e 5.378 de formação e qualificação (crescimento de 4.005\%) em 1984 (Cf. Tabela 2). Dessa forma, podemos constatar que a política de formação do pesquisador foi direcionada, precipuamente, para a pós-graduação em nível de mestrado e doutorado. Evidenciou-se, no Governo Militar, "o caráter estratégico da C\&T para o desenvolvimento econômico do país com a criação do Sistema Nacional de Desenvolvimento Científico e Tecnológico (SNDCT) e da inserção da área no I Plano Nacional de Desenvolvimento (I PND) e nos objetivos do Programa Estratégico de Desenvolvimento (PED)" (OLIVEIRA, 2003, p. 12), com destaque para a política de formação de professores/pesquisadores para a Educação Superior. Segundo Amâncio, Mendonça e Cazar (1996, p. 180), nesse contexto, o Governo Militar, por meio do "Plano de Metas e Bases para ação do Governo (1970-1972)", já demonstrava a tendência de desenvolver a educação científica "o mais breve possível" no Ensino Médio (EM) com a finalidade de descobrir "vocações para a pesquisa".

Para a compreensão desse momento histórico é importante ter presente que a despeito da Capes ter sido criada em 1951, entre este ano e o de 1964, este órgão responsável pela PG stricto sensu fez parte da estrutura do Instituto Nacional de Estudos e Pesquisas Educacionais (INEP) ${ }^{8}$. Com o Governo Militar a Capes ganhou novo status, passando a ser responsável pela organização e fomento da PG, concebida como estratégia acessória ao plano de desenvolvimento de um "Brasil grande". Nesse contexto, foi publicado o Parecer no 977/1965, denominado Parecer Sucupira9, institucionalizando oficialmente a PG stricto sensu, no Brasil (CURY, 2005). Embora inicialmente a principal preocupação da Capes fosse a formação do professor, com o tempo a formação de pesquisadores veio ganhando primazia.

\footnotetext{
7 As bolsas da modalidade formação e qualificação compreendem o doutorado, doutorado sanduíche e o mestrado. A partir de 1964, o CNPq passa a contabilizar as bolsas de IC separadamente das outras modalidades.

8 Atualmente a denominação INEP permanece, porém acrescida do nome do educador Anísio Teixeira.

9 Com o parecer Sucupira, institucionalizou-se no Brasil a PG stricto sensu (mestrado e doutorado) voltada à formação de professores e pesquisadores para ES e a PG lato sensu destinada à especialização/ aperfeiçoamento profissional. O relator do Parecer n 977/65 Newton Lins Buarque Sucupira teve como principal referência o modelo de PG norte-americano. Acesso à versão integral do parecer em Almeida Junior et al. (2005).
} 
Tabela 2. Evolução do número e percentual de bolsas de formação no país, 1963-1984.

\begin{tabular}{|c|c|c|c|c|}
\hline Ano & \multicolumn{2}{|c|}{$\mathrm{IC} / \%$} & \multicolumn{2}{|c|}{ Formação E Qualificação \% } \\
\hline 1963 & 246 & & 131 & \\
\hline 1964 & 157 & -36 & 72 & -45 \\
\hline 1965 & 251 & 60 & 91 & 26 \\
\hline 1966 & 357 & 42 & 142 & 56 \\
\hline 1967 & 426 & 19 & 188 & 32 \\
\hline 1968 & 399 & -6 & 289 & 54 \\
\hline 1969 & 373 & -6 & 500 & 73 \\
\hline 1970 & 378 & 1 & 695 & 39 \\
\hline 1971 & 427 & 13 & 971 & 40 \\
\hline 1972 & 522 & 22 & 1.038 & 7 \\
\hline 1973 & 610 & 17 & 1.236 & 19 \\
\hline 1974 & 600 & -2 & 1.394 & 13 \\
\hline 1975 & 562 & -6 & 1.651 & 18 \\
\hline 1976 & 845 & 50 & 2.536 & 54 \\
\hline 1977 & 878 & 4 & 2.806 & 11 \\
\hline 1978 & 837 & -4 & 3.219 & 15 \\
\hline 1979 & 877 & 5 & 3.523 & 9 \\
\hline 1980 & 1.079 & 23 & 3.695 & 5 \\
\hline 1981 & 1.052 & -2 & 3.876 & 5 \\
\hline 1982 & 1.274 & 21 & 4.544 & 17 \\
\hline 1983 & 1.175 & -8 & 4.947 & 9 \\
\hline 1984 & 1.321 & 12 & 5.378 & 9 \\
\hline TOTAL & 25.967 & & 42.809 & \\
\hline
\end{tabular}

Fonte: Elaboado pelos autores (2017).

A partir do Governo José Sarney (1985-1989), com o estabelecimento da Nova República, as bolsas de IC tiveram um crescimento acentuado, passando de 1.321 bolsas no último ano do governo anterior para 6.349 (387\%) em 1989. Já as bolsas de formação e qualificação continuaram sua trajetória de crescimento, porém, este foi menor, passando de 5.378 em 1984 para 10.361 em 1989 (93\%), reduzindo, desse modo, a diferença em 18 pontos percentuais entre as bolsas de PG (de $80 \%$ para $62 \%$ ) e de IC ( $20 \%$ para $38 \%$ ), conforme a Tabela 3. Esses dados demonstram que houve, no Governo da chamada Nova República, a continuidade da política de priorização da formação inicial de pesquisadores na $\mathrm{PG}^{10}$, embora em menor nível, com o aumento do número de bolsas de IC.

\footnotetext{
${ }^{10}$ Essa política estava sintetizada nos II e III Planos Nacionais de Pós-Graduação (PNPG) e concretizou-se na criação de boa parte dos cursos de mestrado e doutorado (MACHADO, 1999).
} 
Na década de 1990, no Governo Collor ${ }^{11}$ de Mello (1990-1992) e de Itamar Franco (1992-1994), foi criado o Pibic, por meio da Resolução Normativa (RN) $\mathrm{n}^{\circ}$ 005/1993, buscando consolidar a IC como uma das políticas prioritárias na formação de pesquisadores. Anteriormente, a IC era administrada somente pelo CNPq, com as solicitações de bolsas feitas pelos pesquisadores via demanda balcão/bolsas quotas ${ }^{12}$. A criação do Pibic objetivou o "envolvimento dos estabelecimentos de ensino, enquanto instituição, no aperfeiçoamento do Programa" (MACCARIELO, NOVICKI; CASTRO, 2002, p. 87), possibilitando às instituições um meio de formular políticas de pesquisa para a graduação.

Uma das formas de materialização dessa tendência foi o aumento do número de bolsas de IC, passando de 6.349 em 1989, para $15.131 \mathrm{em} 1994$, com um acréscimo de $138 \%$. Esse crescimento pode estar relacionado à "própria normatização do PIBIC [...] uma vez que por meio delas (RNs) todas as IES tiveram a oportunidade de requerer" (SILVA, 2012, p. 74) diretamente as bolsas. O número de bolsas de IC desses primeiros cinco anos da década de 1990 superou os 26 anos anteriores, com o total de 56.448 (1990-1994) e 45.240 (1963-1989) respectivamente. Com essa trajetória houve uma quase equalização do número de bolsas entre a graduação e a pós-graduação, pois o quantum de bolsas de formação e qualificação era de 15.630, representando $51 \%$ do total no último ano do Governo Itamar Franco (Cf. Tabela 3). Dessa maneira, apontando um novo delineamento na política de formação do pesquisador por parte do $\mathrm{CNPq}$, passando a ser também prioritária a IC, com a finalidade de preparar os discentes para que chegassem à PG com conhecimento teórico-metodológico para desenvolvimento de pesquisas.

No Governo Fernando Henrique Cardoso (FHC/1995-2002) prevaleceu a perspectiva de que a educação e o desenvolvimento científico-tecnológico são formas de propiciar maior competitividade à economia do Brasil. Nesse contexto, a IC consolidou-se como prioridade, mesmo com as oscilações do período, com 18.864 bolsas em 2002, representando uma ampliação de 25\% em relação a 1994. Com esse crescimento, a participação da IC aumentou $62 \%$ no total de bolsas no país e as de formação e qualificação diminuíram para $38 \%$ em 2002, como podemos observar na Tabela 4.

\footnotetext{
${ }^{11}$ Nesse Governo, com a utilização de uma retórica neoliberal que defendia o Estado Mínimo, consolidou-se o desmonte do sistema de pesquisa, com a diminuição dos investimentos e a indução para que o setor produtivo e institutos de pesquisa fiquem encarregados pelo desenvolvimento C\&T. A exceção foi à manutenção e o aumento dos investimentos na formação de professores/pesquisadores. O CNPq correu o risco de ser extinto e os recursos para investimentos em pesquisa praticamente inexistiram (GUIMARÃES, 2001).

${ }^{12}$ Concedidas diretamente aos pesquisadores/coordenadores com projetos de pesquisa aprovados pelo CNPq. Essa modalidade integrada aos projetos de pesquisa tem como peculiaridade "que o próprio pesquisador/ orientador é o responsável pela seleção, acompanhamento e avaliação" (PIRES, 2008, p. 78).
} 
Tabela 3. Evolução do número e percentual de bolsas de formação no país, 1984-1994.

\begin{tabular}{lcccc}
\hline Ano & IC/\% & \multicolumn{2}{c}{ Formação E Qualificação \% } \\
\hline 1984 & 1.321 & 21 & 5.378 & 3 \\
1985 & 1.600 & -6 & 5.558 & 7 \\
1986 & 1.510 & 160 & 7.838 & 32 \\
1987 & 3.921 & 50 & 9.293 & 19 \\
1988 & 5.893 & 8 & 10.361 & 11 \\
1989 & 6.349 & 19 & 12.800 & 24 \\
1990 & 7.548 & 21 & 14.178 & 11 \\
1991 & 9.117 & 25 & 13.860 & -2 \\
1992 & 11.440 & 15 & 14.314 & 3 \\
1993 & 13.212 & 15 & 15.630 & 9 \\
1994 & 15.131 & & 115.143 & \\
TOTAL & 77.042 & & & \\
\hline
\end{tabular}

Fonte: Elaborado pelos autores (2017).

Tabela 4. Evolução do número e percentual de bolsas de formação no país - 1994-2002.

\begin{tabular}{lcccc}
\hline Ano & IC/\% & \multicolumn{2}{c}{ Formação E Qualificação \% } \\
\hline 1994 & 15.131 & 24 & 15.630 & 18 \\
1995 & 18.790 & -1 & 18.411 & -12 \\
1996 & 18.761 & 1 & 16.274 & -9 \\
1997 & 18.856 & -7 & 14.748 & -13 \\
1998 & 17.533 & -2 & 12.780 & -10 \\
1999 & 17.120 & 8 & 11.417 & -1 \\
2000 & 18.483 & 2 & 11.361 & 2 \\
2001 & 18.778 & -1 & 11.641 & -2 \\
2002 & 18.864 & & 11.437 & \\
TOTAL & 162.316 & & 123.699 & \\
\hline
\end{tabular}

Fonte: Elaborado pelos autores (2017).

O Governo Luiz Inácio Lula da Silva (2003-2010) manteve o percentual de 62\% das bolsas de IC no total das bolsas voltadas para a formação do pesquisador no país, em comparação com o último ano do governo anterior. Porém, houve um aumento de $63 \%$ no número de bolsas de IC em 2010, em relação a 2002, chegando a 30.826 bolsas (Cf. Tabela 5). Esse crescimento pode ser explicado pela política de inclusão social do Governo e pela busca de identificar precocemente jovens talentos, possibilitando ao bolsista de IC “condições para participar e desenvolver projetos que contribuam para alavancar a economia do país nas diferentes áreas 
do conhecimento, de modo que tal processo possa auxiliar o aluno a tornar-se um profissional qualificado em menor tempo" (SANTOS, 2013, p. 52), sendo produtivo por mais tempo. Para este aumento, foi relevante a criação da ICJ em 2003, normatizada pela $\mathrm{RN} \mathrm{n}^{\circ} 017 / 2006$, em seu Anexo V (CNPq, 2006a) que, em parceria com as Fundações Estaduais de Amparo à Pesquisa (FAPs), passou a conceder bolsas pelo programa IC-Jr aos estudantes do EM e Ensino Fundamental (EF), com o objetivo de propiciar opções de educação científica e tecnológica desde a EB. Ainda observando a Tabela 5, constatamos que a ICJ teve várias oscilações no número de bolsas, no início de sua implementação, porém, comparando as 377 bolsas de 2003 com as $4.053 \mathrm{em}$ 2010, houve um crescimento de 975\%. Além disso, em 2010, o CNPq lança o Pibic-EM (CNPq, [201-?b]) ${ }^{13}$ para o desenvolvimento de projetos de educação científica com estudantes do EM e em parceria com as IES. Sendo assim, um dos diferenciais do Governo Luiz Inácio Lula da Silva, em relação aos anteriores, foi a implementação da IC na EB.

O Governo Dilma Rousseff (2011-2016), por sua vez, deu continuidade a essa política de priorização da IC com um aumento de $45 \%$ nessa modalidade de bolsas, totalizando $211.490 \mathrm{em} 2015$. Dessa forma, em 2015, o percentual de participação da IC, em relação às outras modalidades de bolsas de formação e qualificação, era de $65 \%$. O aumento percentual das bolsas de ICJ, de $163 \%$ (10.672) em 2015, em relação ao último ano do governo anterior, foi determinante nesse quadro (Cf. Tabela 6). Diante desse contexto histórico de uma política de priorização e expansão da IC para a EB, podemos afirmar que, hoje, se consubstancia como política de $\mathrm{Estado}^{14}$. E uma das razões para esse destaque e para a expansão da IC é a necessidade do país de alcançar melhores indicadores de desenvolvimento em Ciência, Tecnologia e Inovação (C, T \& I), preparando os jovens para a incorporação e o manejo das novas tecnologias e para seguir a carreira acadêmica ou científica.

A amplitude da ICJ, alcançada em apenas 13 anos de existência, em comparação com a IC, na graduação, pode ser constatada no Gráfico 1. Com uma participação inicial de $2 \%$, passou para $28 \%$ em 2015 , com algumas oscilações no período de 2003-2015, mas prevalecendo o crescimento no total das bolsas de IC. O valor de R $\$ 100,00$ das bolsas de ICJ, comparativamente ao valor de $\mathrm{R} \$ 400,00$ da

\footnotetext{
${ }^{13}$ O valor da bolsa Pibic-EM desde sua criação em 2003 até os dias atuais mantém-se com o valor de R\$ 100,00 mensais. São critérios para concessão: estar regularmente matriculado em escolas públicas do ensino fundamental ( $8^{\mathrm{a}}$ série ou $9^{\circ}$ ano) e médio ( $1^{\mathrm{a}}$ e $2^{\mathrm{a}}$ séries); não possuir vínculo empregatício; ter frequência igual ou superior à $80 \%$; apresentar histórico escolar; e dedicar no mínimo oito horas semanais para as atividades do projeto (CNPq, 2006, [201-?a], [201?b]). O Pibic-EM segue a mesma normativa da IC-Jr/FAPs, conforme RN-17/CNPq (2006a).

${ }^{14}$ Com o Governo Michel Temer (2016- ) e suas politicas restritivas, embora não tenhamos dados até o momento, precisamos relativizar essa afirmação.
} 
Tabela 5. Evolução do número e percentual de bolsas de formação inicial no país 2002-2010.

\begin{tabular}{lcccccccc}
\hline Ano & IC & \% & ICJ & \% & Total & $\%$ & $\begin{array}{c}\text { Formação E } \\
\text { Qualificação \% }\end{array}$ \\
\hline 2002 & 18.864 & & & & 18.864 & & 11.437 & \\
2003 & 18.238 & -3 & 377 & & 18.615 & -1 & 11.855 & 4 \\
2004 & 19.255 & 6 & 1.876 & 397 & 21.131 & 13 & 12.982 & 9 \\
2005 & 19.912 & 3 & 1.272 & -32 & 21.184 & 1 & 14.133 & 8 \\
2006 & 20.704 & 4 & 787 & -38 & 21.491 & 1 & 15.408 & 9 \\
2007 & 21.025 & 2 & 3.138 & 299 & 24.163 & 12 & 16.049 & 4 \\
2008 & 22.006 & 5 & 3.878 & 24 & 25.884 & 7 & 17.000 & 6 \\
2009 & 24.043 & 9 & 2.464 & -36 & 26.507 & 2 & 18.616 & 10 \\
2010 & 26.773 & 11 & 4.053 & 65 & 30.826 & 16 & 19.213 & 3 \\
TOTAL & 190.820 & & 17.845 & & 208.665 & & 136.693 & \\
\hline
\end{tabular}

Fonte: Elaborado pelos autores (2017).

Tabela 6. Evolução do número e percentual de bolsas de formação inicial no país, 2010-2015.

\begin{tabular}{lcccccccc}
\hline Ano & IC & \% & ICJ & \% & Total & \% & $\begin{array}{c}\text { Formação E } \\
\text { Qualificação \% }\end{array}$ \\
\hline 2010 & 26.773 & & 4.053 & & 30.826 & & 19.213 & \\
2011 & 25.580 & -4 & 7.237 & 79 & 32.817 & 6 & 20.540 & 7 \\
2012 & 28.414 & 11 & 7.977 & 10 & 36.391 & 11 & 19.238 & -6 \\
2013 & 26.668 & -6 & 9.334 & 17 & 36.002 & -6 & 17.749 & -7 \\
2014 & 26.970 & 1 & 10.095 & 8 & 37.065 & 3 & 17.701 & 0 \\
2015 & 27.717 & 3 & 10.672 & 6 & 38.389 & 4 & 17.356 & 2 \\
TOTAL & 162.122 & & 49.369 & & 211.490 & & 111.797 & \\
\hline
\end{tabular}

Fonte: Elaborado pelos autores (2017).

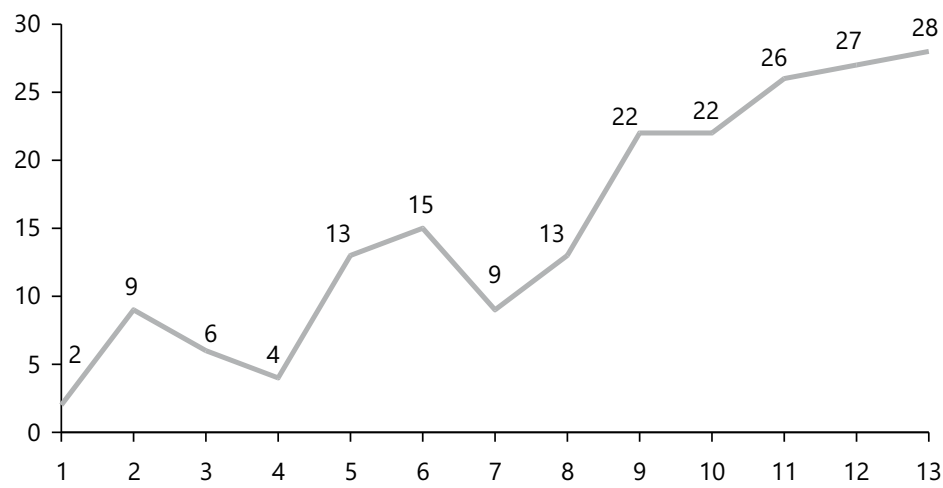

Gráfico 1. Participação percentual da ICJ no total das bolsas de IC, 2003-2015. Fonte: Elaborado pelos autores (2017). 
IC na graduação - diferença de $300 \%$-, ajuda a explicar essa tendência, pois os investimentos necessários na IC voltada para a EB são muito menores. Ademais, os dados revelam que a IC na graduação e, nos últimos anos, a ICJ tem despertado o interesse dos estudantes pela pesquisa (SANTOS, 2011).

\section{A ICJ e a convergência entre o CNPq e a Capes}

A IC, como uma preocupação que passa a incorporar os alunos da EB, pelo $\mathrm{CNPq}$, no Brasil, é recente. No entanto, na revisão de literatura sobre o assunto detectamos que, em 1986, foi criado, na Escola Politécnica da Saúde, Joaquim Venâncio/Fundação Oswaldo Cruz (EPSJV/FIOCRUZ), o Programa de Vocação Científica (Provoc), considerado o primeiro programa voltado à IC, no EM do Brasil, com a finalidade de propiciar a formação inicial de jovens estudantes na área científica (EPSJV, [200-?]). A partir dessa experiência de vanguarda foi criada, pelo CNPq, a ICJ - com os programas: IC-Jr/FAPs; Pibic-EM; o PIC-Obmep ${ }^{15}$ - e pela Capes, o Programa Bolsas Jovens Talentos para a Ciência (PJT-IC) ${ }^{16}$.

No Brasil, a desigualdade continua sendo determinante para o nível de acesso, a permanência e o sucesso escolar dos alunos oriundos da "classe que vive do trabalho" (ANTUNES, 2003), pois, segundo dados do Instituto Brasileiro de Geografia e Estatística (IBGE), de 2014, 55\% dos jovens de 14 a 17 anos frequentavam o EM em 2013, sendo que 42\% ainda estavam no EF ou não estavam frequentando a escola (IBGE, 2015). Nos últimos anos está havendo uma progressiva ampliação do acesso. Por exemplo, como em 2013 o acesso ao EM era de 55\%, aumentou em 11 pontos percentuais ao compararmos com os $44 \%$ de 2004. Porém, essa melhora "não eliminou os problemas relacionados à qualidade do ensino" (ZAGO, 2006, p. 232), interferindo nas expectativas dos jovens em relação à entrada e permanência na ES. Nesse contexto, no Brasil, em geral, alunos das classes populares não almejam o ingresso na ES, pois é fato histórico que a universidade faz parte da vida de quem não depende apenas do seu trabalho para garantir o seu sustento e o da sua família. Em uma sociedade em que a ES é um privilégio de poucos, a maioria abre mão de ingressar nas IES em virtude da tradição histórica de exclusão. Indicadores sociais do INEP, de 2012 (FPA, 2014), apontam que 34\% dos jovens de 18 a 24 anos concluíram o

\footnotetext{
${ }^{15}$ O PIC-Obmep é uma parceria do CNPq com o Instituto de Matemática Pura e Aplicada (IMPA), que oferece bolsas para estudantes premiados na Olimpíada Brasileira de Matemática das Escolas Públicas (Obmep) e tem por finalidades: "fortalecer o ensino de matemática nas Escolas Públicas; motivar os alunos na escolha profissional pelas carreiras científicas e tecnológicas; despertar nos alunos o gosto pela matemática e pela ciência em geral." (CNPq, [201-?a]).

16 O PJT foi lançado em 2012 pela Capes com o objetivo de "preparar os estudantes para" o Programa Institucional de Bolsas de Iniciação à Docência (Pibid), Pibic e o Programa Ciência Sem Fronteiras (CAPES, 2014).
} 
EM, e $21 \%$ tiveram acesso à ES, ou seja, $45 \%$ dos jovens em idade de acessar a ES não tiveram essa oportunidade por não terem finalizado o $\mathrm{EM}^{17}$.

Nesse contexto, uma das razões para a criação e expansão da ICJ é a necessidade de desenvolver nos jovens o gosto pela ciência, de identificar, precocemente ${ }^{18}$, talentos potenciais e de suscitar o desejo de seguir a carreira acadêmica e científica em jovens estudantes de escolas públicas, pois, "se começarmos a trabalhar com o jovem bem cedo, quando ele está ingressando no ensino médio, teremos mais condições de estimular, incentivar e dar o apoio necessário para que ele comece a construir sua carreira profissional" (FERREIRA, 2010, p. 49). Logo, "essa iniciativa visa a manter uma parcela da juventude na escola por um número de anos maior, qualificando-a e estimulando-a para esse conhecimento" (BONELLI, 2010, p. 107). Ainda existem áreas de formação e pesquisa, como as engenharias, no Brasil, nas quais há carência de acadêmicos e de profissionais, e a implementação da ICJ visa a criar também o interesse pela área.

Esse processo, entretanto, somente pode ser compreendido se tivermos presente a implementação da PG stricto sensu, a forma como esta veio sendo avaliada e financiada e a relação da formação de mestres e doutores com o tempo ou aquilo que se consagrou nos processos avaliativos como Tempo Médio de Titulação (TMT). Se falávamos que a IC é uma preocupação recente, a questão da existência de um sistema de PG não é diferente.

Como vimos anteriormente, o Regime Militar visualizou na Capes um órgão auxiliar para a consecução das metas de um "Brasil grande". Mas é somente com a transformação da Capes em Fundação, no início da década de 1990, que esta conta com a autonomia que ultrapassa a autonomia universitária, prevista constitucionalmente. Na verdade, a Capes, ao ser responsabilizada pela elaboração dos Planos Nacionais de Pós-Graduação (PNPGs), a partir da década de 1970, e de acoplar o financiamento à avaliação, no final dos anos de 1980 e início de 1990, assume uma forma de atuação que a caracteriza muito mais como uma agência reguladora (SGUISSARDI, 2013), do que, propriamente, como uma "Coordenação" (denominação que substituiu "Campanha", ainda nos primórdios da Instituição). O concreto é que, ao juntar a avaliação e o financiamento, a Capes avocou a si a responsabilidade de avaliar e financiar a PG, sendo que, gradativamente,

\footnotetext{
${ }^{17}$ Em relação ao ingresso na ES algumas mudanças podem ser constatadas a partir das políticas de ações afirmativas. São poucos os dados disponíveis ainda a este respeito. Esta mudança, contudo, não foi/é suficiente para inverter a tendência.

${ }^{18}$ Ao falarmos "precoce", aqui referimo-nos ao fato que houve uma antecipação, na última década, da formação inicial de pesquisadores a partir da EB com a ICJ, uma vez que anteriormente predominava a iniciação à formação de pesquisadores na universidade.
} 
a avaliação foi sendo descaracterizada da sua função formadora, ganhando supremacia a classificação e os rankings, com compensações aos Programas de PG que alcançassem as metas e prejuízos, em forma de número de bolsas e de outros financiamentos, àqueles que não satisfizessem os critérios daquele tipo de avaliação. E um dos indicadores passou a ser o TMT, traduzindo-se em dois (2) anos para concluir o mestrado e quatro (4) para o doutorado. Isto é, de um tempo laxo passa-se a um tempo mais restrito e regulado.

Ora, esta questão do tempo, nas primeiras décadas de existência e funcionamento da PG, era bastante relativizada, inclusive com mestres e doutores alargando excessivamente os prazos para concluir seus trabalhos, e muitos sequer concluíram seus cursos, ao não defenderem suas dissertações e teses. Em período mais recente, nomeadamente a partir dos anos de 1990, a acoplagem da avaliação ao financiamento tornou mais draconianas as exigências e as consequências em termos de o pós-graduando concluir ou não o curso, uma vez que a recompensa-punição para o estudante, para o curso, para seu orientador, decorria do resultado do ingresso e da conclusão do curso. Enfim, o fluxo precisava ser mantido.

Como podemos verificar, há um aligeiramento ${ }^{19}$ na formação de pesquisadores e de outros profissionais, com o consequente aumento do número de investigadores e do seu tempo de atuação. Esse processo evidencia a convergência "entre o implementando anteriormente pela Capes com o Processo de Bolonha ${ }^{20} \mathrm{em}$ termos da política de redução do tempo de formação de pesquisadores e do predomínio da lógica do produtivismo acadêmico" (ARAÚJO; OLIVEIRA, 2014, p. 98), com a finalidade de determinar uma temporalidade mundial (NERAD; HEGGELUND, 2008) em detrimento dos tempos locais e individuais. Desse modo, ao priorizar a quantidade e a diminuição do tempo de formação dos pesquisadores - eis o aligeiramento! -, é que se espera que estes, cada vez em tempo mais reduzido, possam disputar postos no mercado de trabalho e inserir-se em processos de pesquisa e inovação tecnológica. E isto tanto vem ao encontro da "agenda globalmente estruturada para a educação" (DALE, 2001) quanto intensifica uma das facetas do produtivismo acadêmico e de um particular "capitalismo acadêmico" (RHOADES; SLAUGHTER, 2004; PARASKEVA et al., 2009) dominante

\footnotetext{
19 Entendemos por "aligeiramento" a antecipação do processo de iniciação à formação de pesquisadores desde a EB, de um lado, e, de outro, a redução do tempo de formação de mestres e doutores (TMT). De acordo com Duarte (2012) as políticas educacionais atuais, "têm apontado para um aligeiramento da formação intelectual" dos educadores e pesquisadores, contribuindo "para uma visível perda na qualidade da formação teórica destes profissionais" (p. 82). Está política indutiva tem trazido implicações como o "mal-estar provocado pelo fetiche do conhecimento-mercadoria e seu canto da sereia - o produtivismo" como se pode ver em Trein e Rodrigues (2011, p. 786).

${ }^{20}$ Para um aprofundamento sobre o Processo de Bolonha, ver Bianchetti (2015). Adicionalmente Moraes (2006), aponta para a conciliação entre o projeto de universidade global expresso no Processo de Bolonha e a política para o ensino superior brasileiro.
} 
nas políticas para a ES, que prioriza a quantidade, seja no tocante à formação profissional, seja no que diz respeito à produção acadêmico-científica (MORAES, 2012). Nesse contexto produtivista e de precarização do trabalho docente e de pesquisa, Bosi afirma que as "IES no Brasil carecem de problematização, reflexão e denúncias sistemáticas” (2007, p. 1519).

Outra implicação desta redução do tempo de formação pode ser o "recuo da teoria", uma vez que nessa política de tempo as possibilidades de reflexão epistemológica aprofundada ficam prejudicadas, prevalecendo "o "saber fazer" (MORAES, 2003), consubstanciando a "regressão teórica", com a "paralisia da crítica" e a "ultrapresentificação do hoje", não se levando em consideração o processo histórico de constituição da realidade (WARDE, 2012), contribuindo para a predominância de "um utilitarismo que engole a imaginação" (JACOBY, 2001, p. 230), sem contar os prejuízos a uma formação de caráter aprofundado e universalista.

Nesse contexto, há um descompasso entre o tempo necessário para uma formação sólida e ampla dos pesquisadores e o tempo que essa política de estado normatiza, institucionaliza e impõe. Essa política das instituições, de Estado e dos Organismos Internacionais (OI) condiciona a forma como o tempo deveria ser vivenciado, pois, como assevera Araújo (2011):

Neste período a interrogação da articulação entre Estado e sociedade e entre Estado e indivíduo faz-se através da interpelação do papel do Estado na regulação do tempo: do tempo diário, definível em sentido métrico; do tempo de vida, definível através das idades de entrada, permanência e saída do sistema, e do tempo histórico que, na origem, definiria o primeiro horizonte da prática política (p. 21).

Nesse sentido, podemos dizer que o Estado brasileiro tem buscado estabelecer, com elementos de formalidade, via indução de políticas públicas, como a ICJ, que o tempo de iniciar a pesquisa deva ser na EB, antecipando uma fase que antes ocorria na graduação, atendendo aos ditames produtivistas do mercado e às diretrizes de OI, demonstrando seu market-like bahaviors (RHOADES; SLAUGHTER, 2004, p. 37) e impondo uma disciplina do tempo (THOMPSON, 1998).

É nessa conjuntura que se compreende que o CNPq e algumas FAPs, como exemplarmente é a FAP do Estado de São Paulo (FAPESP), passam a financiar pós-graduandos. Paralelamente, primeiro aquele, depois estas, começam a ampliar o leque de financiamentos, seja para pesquisadores de forma individual, seja para grupos de pesquisa e, gradativamente, passam a formatar iniciativas, Programas 
para estimular, incentivar o engajamento de investigadores iniciantes, desde a graduação, como é o caso do Pibic. Por meio deste, atribuía-se, em especial, com a vinculação de graduandos a Projetos de Investigadores, bolsas a fim de que, desde o curso de graduação, o estudante se iniciasse nos processos de investigação, agregando-se aos trabalhos dos investigadores e seus grupos de pesquisa. Com a institucionalização e expansão da IC há, de certa forma, uma remediação do TMT retirado do período de formação de mestres e doutores e "verifica-se que o Programa de IC é estratégico para indução ao produtivismo acadêmico na graduação" (SANTOS, 2013, p. 50), formando precocemente jovens pesquisadores na graduação e na EB.

A partir dos anos 2000, mais duas iniciativas vão somar-se à IC como estratégias para ampliar o leque de abrangência de formação de investigadores, com repercussões no tempo de treinamento, formação, término dos cursos, a fim de que o pós-graduando conclua seus cursos e se engaje cada vez mais cedo no mundo da produção, agregando valor, seja ao seu salário, seja aos seus inventos, aos produtos para serem incorporados no circuito da mercadoria, e tragam benefícios para o (neo) trabalhador e o país. Uma das iniciativas é o Pibic-EM e, a partir de FAPs, a IC-Jr. Por conseguinte, a política aponta no sentido de inserir cada vez mais cedo o jovem no savoir faire da investigação a fim de que ele, como está expresso pelo CNPq (2006b, [201-?b]), se instrumentalize para ingressar, com maior "qualificação" em investigação, na PG.

A outra iniciativa, mas que pode ser apreendida como complementar, foi a criação da Nova Capes, a qual, conforme anunciado no site do órgão (www.capes.gov.br), "além de coordenar o alto padrão do Sistema Nacional de PG brasileiro também passa a induzir e fomentar a formação inicial e continuada de professores para a EB" (LOPES; ENS 2013, p. 12488), por meio de programas como o Pibid e o Plano Nacional de Formação de Professores da Educação Básica (Parfor). Desta maneira, passa-se a interferir na formação, via indução na investigação, seja diretamente pelas bolsas aos estudantes, seja pelo suporte à qualificação dos investigadores e à formação de professores de todos os níveis, visando expressamente a uma qualificação dos envolvidos nesse processo.

Em síntese, o CNPq, como um dos principais órgãos de fomento à formação de pesquisadores, privilegia, na década de 1990 e na primeira década do atual, a concessão de bolsas de IC como estratégia de formação inicial do pesquisador, colaborando para a redução do TMT de mestres e doutores e contribuindo para o estabelecimento da infraestrutura científica e tecnológica do país. Porém, não há como deixar de perceber o quanto a questão da 
diminuição do tempo para a formação interfere na classificação dos alunos para ingressar na PG, na classificação e no "rankeamento" dos Programas e na consequente repercussão nos financiamentos, bem como no próprio ranking do país, no conjunto dos países que se submetem a mecanismos internacionais de avaliação e classificação.

Dessa maneira, a política do CNPq de investir na IC, inclusive na EB, e da Capes, buscando a diminuição do TMT e de focar a atuação, a partir de 2009, na formação de professores para a EB, por meio do Parfor e do Pibid, aponta para uma sintonia e articulação no aligeiramento da formação do professor pesquisador e para uma convergência, que podemos caracterizar como sistêmica, de políticas direcionadas para a EB. Essa política voltada para a EB e para maior interação entre os níveis de ensino, no Brasil, é ressaltada pelo ex-presidente da Capes, Jorge Guimarães, ao apontar que um dos critérios de avaliação é a integração dos PPG com a EB "e a formação de professores para esse segmento" (CAPES, 2013). Por conseguinte, há um aprofundamento da afirmação de Pires de que a "a Capes e o CNPq vão caminhando juntas na formulação e execução de uma política de formação de pesquisadores" (2008, p. 270).

De outro ponto de vista, contudo, o que se evidencia é que essa política de tempo pode estar em descompasso com a necessidade de cultivar a existência de tempos experimentais, probatórios nos diversos tempos e temporalidades de formação e constituição de uma carreira acadêmica e científica. Dessa forma, fica prejudicada a constituição da IC como um tempo probatório, composto de processos e dinâmicas que têm durações e temporalidades próprias, em que o sujeito se relaciona com os outros. Essas interações com experiências e temporalidades diferentes - orientadores, pós-graduandos, seus pares e famílias - são determinantes no caminho da materialização da "confiança ontológica" (GIDDENS, 1991, p. 84) e da construção do habitus acadêmico (BOURDIEU, 1974, 2011).

\section{O Pibic e o risco de extinção do Pibic-EM na IES pesquisada}

A UFSC concede bolsas de IC com recursos próprios desde 1987, por meio das Bolsas de Iniciação à Pesquisa (BIPI), regulamentadas pela Resolução no 049/ Conselho de Ensino, Pesquisa e Extensão (CEPE)/1987. Em 1990, a IES aderiu ao Pibic/CNPq. Com isso aumentou o número de bolsas de IC, que era de 182 em 1987 para 403 em 1995, correspondendo a um crescimento percentual de $121 \%$, como vemos na Tabela 7 . 
Tabela 7. Pibic e BIPI IES: Distribuição do número de bolsas solicitadas e concedidas, 1987-1995.

\begin{tabular}{lccccc}
\hline Ano & $\begin{array}{c}\text { Solicitadas } \\
\text { BIPI }\end{array}$ & Concedidas & $\begin{array}{c}\text { Solicitadas } \\
\text { PIBIC }\end{array}$ & Concedidas & Total \\
\hline 1987 & N/D & 182 & - & - & 182 \\
1988 & N/D & 214 & - & - & 214 \\
1989 & N/D & 217 & - & - & 217 \\
$1990 / 1991$ & 263 & 220 & 239 & 50 & 270 \\
$1991 / 1992$ & 229 & 220 & 153 & 97 & 317 \\
$1992 / 1993$ & 237 & 220 & 293 & 100 & 320 \\
$1993 / 1994$ & 245 & 130 & 387 & 173 & 303 \\
$1994 / 1995$ & 217 & 130 & 490 & 273 & 403 \\
\hline
\end{tabular}

Fonte: Elaborado pelos autores (2017).

A partir do período 1995-1996, a UFSC fundiu o BIPI e o Pibic, por meio da Resolução ${ }^{\circ}$ 032/CEPE/1995, atendendo à exigência do CNPq. No Gráfico 2, mais adiante, constatamos pequenas oscilações no número de bolsas de IC no período de 1995 a 2004, com a média de 400 bolsas. Já de 2005 a 2015 houve uma trajetória de crescimento, passando-se de 448 para 793 bolsas, um aumento de 77\%. Em 2005, a IES inclui as bolsas do Programa Institucional de Iniciação em Desenvolvimento Tecnológico e Inovação (Pibiti ${ }^{21}$ - direcionadas à iniciação dos discentes na área tecnológica e inovação de interesse do setor produtivo - no cômputo geral das bolsas de IC, contribuindo para essa trajetória de crescimento. Além disso, a extensão numérica da IC na IES é maior do que apresentam esses dados, pelos seguintes fatores: professores/orientadores bolsistas de Produtividade em Pesquisa $(\mathrm{PQ})^{22}$ possuem projetos de investigação aprovados pelo $\mathrm{CNPq}$, com bolsas de IC agregadas; e em 2005 a UFSC criou o Programa Bolsista Voluntário em Iniciação Científica ${ }^{23}$ (UFSC, 2010), com 456 alunos voluntários em 2016.

Outra questão que chama atenção, na Tabela 7 e no Gráfico 2 apresentados, diz respeito ao fato de que, desde o período de 1990-1991, em que foram contabilizadas as solicitações, o número de bolsas de IC concedidas é inferior à demanda. Como exemplo, em 2015-2016 foram solicitadas 1.256 bolsas e

${ }^{21}$ O PIBITI, criado em 2005, no Governo Lula da Silva, é normatizado pela RN n 017/2006, Anexo VI. O PIBIT possui a finalidade de "estimular estudantes do ensino técnico e superior ao desenvolvimento e transferência de novas tecnologias e inovação" (CNPq, 2006a), ou seja, "a finalidade do programa é enriquecer a capacidade de inovação das empresas no país" (SANTOS, 2013, p. 49).

22 Em 2016, a universidade pesquisada teve 430 professores/pesquisadores bolsistas PQ (UFSC, 2017).

${ }^{23}$ Esse programa tem por objetivo "estimular estudantes da graduação que estão desenvolvendo atividades de pesquisa, sem terem sido contemplados com a quota de bolsas de IC". Assim, os alunos não recebem bolsa, mas ao final da pesquisa é lhes conferido um certificado de participação (UFSC, 2010, p. 1). 


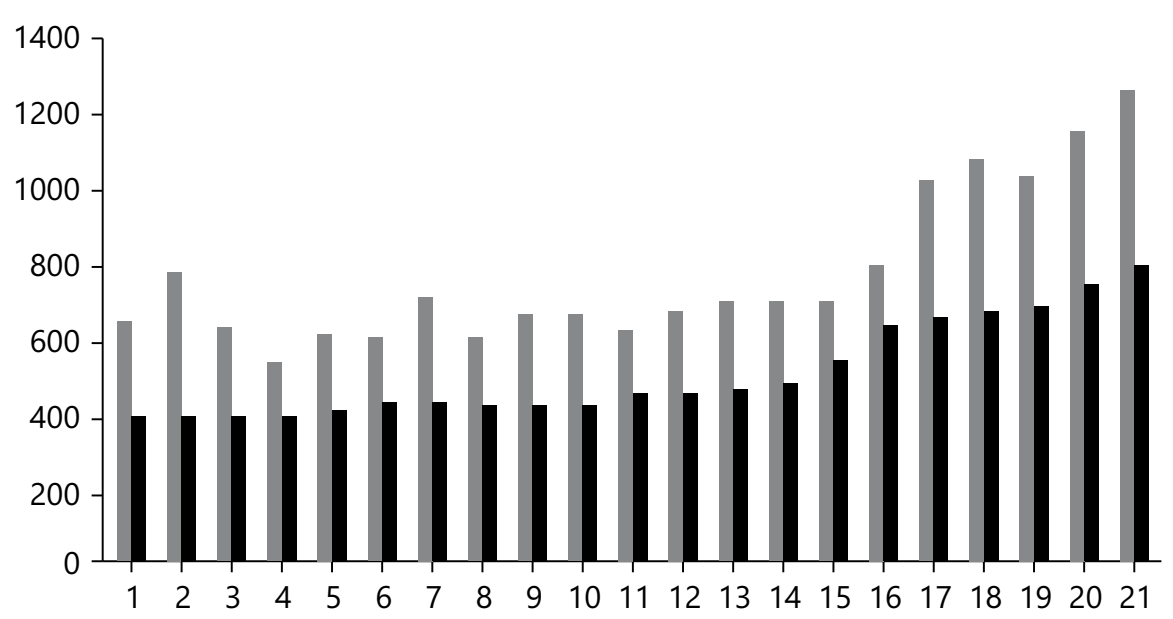

Gráfico 2. Pibic/IES: Diferenças entre bolsas de IC solicitadas e aprovadas - 1995 a 2015. Fonte: Elaborado pelos autores (2017).

concedidas 793 , ou seja, houve uma demanda reprimida de $42 \%$. No entanto, mesmo diante do fato de apenas 3\% dos 27.250 alunos da graduação presencial da UFSC em 2015 participarem da IC, é consenso a sua importância para a formação do pesquisador e para a iniciação na produção do conhecimento, aprimorando a "habilidade metodológica do aluno de graduação, à medida que aprende a lidar com dados, tabelas, questionários, teorias" (DEMO, 2009, p. 2).

O Pibic, como uma experiência exitosa na graduação, também poderia ter essa repercussão na EB e, assim, aprofundaria a relação das universidades com as escolas de EB. Nesse sentido, desde o início dos anos 90 do século passado, Demo (1990, 1997, 2009) discute a importância da pesquisa como princípio científico no caminho da construção do conhecimento e como princípio educativo na direção da formação do espírito científico na educação básica.

Na UFSC, o Pibic-EM estabeleceu-se, em 2010-2011, com 92 bolsas em cinco escolas da rede estadual de ensino, duas da rede municipal e uma da rede federal. No período de 2012-2013 foram utilizadas 87 bolsas. Já no período de 2014-2015, as bolsas implementadas baixaram para 83 . Além do decréscimo de $35 \%$ no número de bolsas disponibilizadas no período 2010-2015, nem todas as bolsas disponíveis foram utilizadas, havendo um saldo de 42 bolsas em 2010-2011, de 13 no período de 2012-2013, e de quatro no último período (2014-2015), conforme podemos visualizar nas Tabelas 8,9 e 10 . 
Tabela 8. Pibic-EM na UFSC: número de bolsas distribuídas e concedidas por campi/ escola, 2010-2011.

\begin{tabular}{lccc}
\hline CAMPI/Escola & $\begin{array}{c}\text { Bolsas } \\
\text { distribuídas }\end{array}$ & $\begin{array}{c}\text { Bolsas } \\
\text { Utilizadas }\end{array}$ & Saldo \\
\hline CAMPUS CENTRAL & 99 & 61 & 38 \\
Colégio de Aplicação & 50 & 36 & 14 \\
EEB Getúlio Vargas & 25 & 17 & 08 \\
EEB Simão Hess & 18 & 05 & 13 \\
EEB Jurema Cavalazzi & 03 & 02 & 01 \\
EEB Ildefonso Linhares & 03 & 01 & 02 \\
CAMPUS ARARANGUÁ & 25 & 22 & 03 \\
EEB Profa. Maria Garcia Pessi & 25 & 22 & 03 \\
CAMPUS CURITIBANOS & 10 & 09 & 01 \\
Núcleo Municipal do Campo Leoniza Carvalho Agostini & 05 & 04 & 01 \\
Núcleo Municipal Getúlio Vargas & 05 & 05 & 0 \\
Total & 134 & 92 & 42 \\
\hline
\end{tabular}

Fonte: Elaborado pelos autores (2017).

Tabela 9. Pibic-EM na UFSC: número de bolsas distribuídas e concedidas por campi/escola, 2012-1013.

\begin{tabular}{lccc}
\hline CAMPI/Escola & $\begin{array}{c}\text { Bolsas } \\
\text { distribuídas }\end{array}$ & $\begin{array}{c}\text { Bolsas } \\
\text { Utilizadas }\end{array}$ & Saldo \\
\hline CAMPUS CENTRAL & 47 & 47 & 0 \\
Colégio de Aplicação & 37 & 37 & 0 \\
EEB Getúlio Vargas & 06 & 06 & 0 \\
EEB Simão Hess & 01 & 02 & 0 \\
EEB Jurema Cavalazzi & 01 & 01 & 0 \\
EEB Altamiro Guimarães & 01 & 01 & 0 \\
CAMPUS ARARANGUÁ & 20 & 20 & 0 \\
EEB Profa. Maria Garcia Pessi & 20 & 20 & 0 \\
CAMPUS CURITIBANOS & 10 & 10 & 0 \\
Núcleo Municipal do Campo Leoniza Carvalho Agostini & 05 & 05 & 0 \\
Núcleo Municipal Getúlio Vargas & 05 & 05 & 0 \\
CAMPUS JOINVILLE & 10 & 10 & 0 \\
EEB Jandira D'Avila & 07 & 07 & 0 \\
EEM Deputado Nagib Zattar & 03 & 03 & 0 \\
Total & 100 & 87 & $13^{24}$ \\
\hline
\end{tabular}

Fonte: Elaborado pelos autores (2017).

${ }^{24}$ Essas 13 bolsas de saldo não foram redistribuídas para os/as campi/escolas. 
Tabela 10. Pibic-EM na UFSC: número de bolsas distribuídas e concedidas por campi/escola, 2014-2015.

\begin{tabular}{lccc}
\hline CAMPI/Escola & $\begin{array}{c}\text { Bolsas } \\
\text { distribuídas }\end{array}$ & $\begin{array}{c}\text { Bolsas } \\
\text { Utilizadas }\end{array}$ & Saldo \\
\hline CAMPUS CENTRAL & 39 & 35 & 4 \\
Colégio de Aplicação & 33 & 31 & 2 \\
EEB Getúlio Vargas & 06 & 04 & 2 \\
CAMPUS ARARANGUÁ & 23 & 23 & 0 \\
EEB Profa. Maria Garcia Pessi & 16 & 16 & 0 \\
EEB Apolônio Ireno Cardoso & 07 & 07 & 0 \\
CAMPUS JOINVILLE & 25 & 25 & 0 \\
EEB Jandira D'Avila & 11 & 11 & 0 \\
EEM Deputado Nagib Zattar & 02 & 02 & 0 \\
EEB Osvaldo Aranha & 06 & 06 & 0 \\
IFSC Joinville & 06 & 06 & 0 \\
Total & 87 & 83 & 4 \\
\hline
\end{tabular}

Fonte: Elaborado pelos autores (2017).

Os dados das tabelas ${ }^{25}$ mencionadas apontam uma tendência de "quase extinção" do Pibic-EM na UFSC, situação oposta, por exemplo, à do Pibic da graduação, em que a demanda de bolsas é maior que a oferta. Entre as causas dessa situação estão: a baixa adesão dos orientadores, que dispõem de pouco tempo para orientação; as limitadas formas de divulgação do Programa; a precária infraestrutura física e as limitadas condições de trabalho dos professores, principalmente das escolas estaduais e municipais.

Outra questão que chama atenção nos dados apresentados nas Tabelas 8,9 e 10 é a diminuição de cinco para duas escolas participantes no campus Central, com a consequente diminuição de 61 (2010-2011) para 35 bolsas do Pibic-EM no último período (2014-2015), mesmo com o maior número de bolsas recebidas pelo Colégio de Aplicação (CA). No período de 2013-2014, há a adesão do campus/escolas de Joinville ao Programa, embora em 2014-2015, o campus de Curitibanos não tenha aderido ao Programa. Tal cenário aponta que o "dever da instituição" (MARCUSCHI, 1996, p. 5) está fragilizado e exige articulações por parte do CNPq e da Propesq, visando a evitar a extinção do Programa. ${ }^{25}$ Em relação a 2016 embora ainda não se tenha dados sobre a utilização, foram concedidas 89 bolsas do
Pibic-EM. 


\section{Considerações finais}

Como vimos, desde a criação do CNPq em 1951 houve investimentos em bolsas de IC. Porém, nessa trajetória de investimentos na formação inicial de pesquisadores foram detectados avanços e recuos dependendo das prioridades dos Governos, do contexto econômico, político e social do país e do crescimento do Sistema Nacional de Desenvolvimento Científico e Tecnológico (SNDTC). Um dos destaques ocorreu no Governo Collor-Itamar que alçou a IC a um programa, com a criação do Pibic, dessa forma, estabelecendo a IC como área prioritária de formação de pesquisadores.

No Governo FHC são introduzidas políticas de caráter sistêmico e aprofundadas nos Governos Lula da Silva e Dilma Rousseff. Além, da priorização da IC na graduação, nas políticas, direcionadas para a aproximação entre a ES e a EB, foram destaques a criação da Nova Capes, em 2007, com as bolsas PIBID, PJT-IC, e do CNPq, com as bolsas de ICJ, em 2003. Nesse aspecto, há uma convergência das diretrizes do CNPq e da Capes, voltadas para essa articulação entre as escolas e as universidades. Agregue-se a estas iniciativas as FAPs que, em parceria com o CNPq, concedem bolsas de IC-Jr.

Em relação às motivações para criação da ICJ, em um ambiente de produtivismo acadêmico hegemônico, nas universidades e nos institutos de pesquisa, destaca-se a preocupação em descobrir talentos potenciais e incentivar os jovens a seguir a carreira acadêmico-científica já na EB, aligeirando o ingresso dos estudantes na graduação e pós-graduação, entre outros aspectos, visando a reduzir o TMT. Essa busca de jovens talentos é limitada a "poucas universidades e cursos de PG", voltados na atualidade para excelência acadêmica (SAVIANI, 2010, p. 15).

Nesse sentido, a ICJ é uma política focal e meritocrática (VALLE; RUSCHEL, 2009), orientada para a descoberta de jovens "talentos" nas escolas públicas. Diante dessa lógica meritocrática, as possibilidades de expansão da ICJ são reduzidas. Por outro lado, a necessidade de qualificar a EB, aumentando o número de concluintes do EM, é outra razão para essa política de aproximação entre escola e universidade e de fomento à ICJ, pois o número de estudantes que terminam o EM na idade considerada apropriada é menor do que o número de vagas para a ES. A perdurar essa situação, a tendência é a falta de estudantes para acessar a graduação, portanto, de demanda qualificada para a PG, com repercussão na formação de professores e pesquisadores.

Na UFSC a utilização de todas as bolsas disponíveis e a ampliação do número delas é um dos desafios para os formuladores dessa política, da coordenação do 
Pibic-EM, dos professores orientadores e das escolas, pois o número médio atual, de 87 bolsas usadas, atendia, em 2011 , somente $0,03 \%$ do total de 250.780 alunos do EM no estado de Santa Catarina (COSTA, 2013). Assim, o Pibic-EM "dá oportunidade apenas a um grupo seleto, aqueles selecionados para o privilégio de viver essa experiência - que obviamente não está difundida no ensino médio de maneira geral" (BONELLI, 2010, p. 111). Um dos riscos é o isolamento, ou seja, o Pibic-EM, se for operacionalizado "de modo isolado e/ou pouco expandido, produzem avanços, mas sem a qualidade de uma integração institucional mais ampla" (CURY, 2004, p. 788), por exemplo, entre as escolas e as universidades, conspirando em relação às possibilidades de constituição de um "círculo virtuoso" entre níveis de ensino.

Entretanto, o processo de constituição e implementação dessa política está fazendo com que, neste momento histórico, possamos dizer que a IC é uma das políticas de Estado com ramificações na EB, na graduação e na PG, via CNPq, Capes, FAPs e IES. Em relação à ICJ, podemos dizer que há uma preparação do jovem para o mundo científico, apresentando elementos e potencial de um círculo virtuoso entre a universidade e as escolas, porém, o Pibic-EM na UFSC, ao contrário do Pibic da graduação, corre o risco de extinção, haja vista a trajetória de diminuição constante das bolsas e da não utilização de todas as disponibilizadas. 


\title{
Junior Scientific Initiation: challenges to the materialization of a virtuous circle
}

\begin{abstract}
The purpose of this article is to analyze the trajectory of the institutionalization of Scientific Initiation and Junior Scientific Initiation grant programs in the country and, particularly at Federal University of Santa Catarina, Brazil. To do so, methodologically, we conducted a document analysis of laws, indicators and reports from $\mathrm{CNPq}$ and from the institution of higher education where the study was conducted. The reasons for the policy to approximate higher education (IES) and basic education are to improve levels of permanence and the success of students and to develop a taste for science. At the IES where the study was conducted, the failure to use all of the Scientific Initiation Grants for High School as part of the Junior Scientific Initiation program points to a reflux in the program.
\end{abstract}

Keywords: ICJ/Pibic-EM. Scientific and educational policy. School-university approximation.

\section{Iniciación Científica Júnior: retos a la materialización de un círculo virtuoso}

\section{Resumen}

Este articulo tiene por finalidad analizar la trayectoria de la institucionalización de la Iniciación Cientifica (IC) y de la Iniciación Científica Júnior (ICJ) en el país y, particularmente, en la Universidad Federal de Santa Catarina, Brasil. Para ello, metodológicamente realizamos el análisis documental de leyes, indicadores e informes del CNPq y de la Institución de Enseñanza Superior (IES) donde fue efectuada la investigación. Las razones para la politica de aproximación entre la Educación Superior y la Educación Básica están: en la mejora de los niveles de permanencia y en el éxito de los estudiantes; y en el desarrollo del gusto por la ciencia. En la IES donde fue realizada la investigación, la no utilización de todas las becas del Programa Institucional de Iniciación Científica de la Enseñanza Media, como parte de la ICJ, señala la tendencia de reflujo del Programa.

Palabras-clave: ICJ/Pibic-EM. Política cientifica y educacional. Aproximación escuelauniversidad. 


\section{Referências}

ALMEIDA JUNIOR, A. et al. Parecer CFE n ${ }^{\circ}$ 977/65, aprovado em 3 dez. 1965. Revista Brasileira de Educação, Rio de Janeiro, n. 30, p.162-173, set./ dez. 2005.

AMÂNCIO, A. M.; MENDONÇA, J. V. de; CAZAR, R. M. Ciência, educação e ensino de segundo grau: realidades e desafios. In: ESCOLA POLITÉCNICA DE SAÚDE JOAQUIM VENÂNCIO (Org.). Formação de pessoal de nível médio para a saúde: desafios e perspectivas. Rio de Janeiro: Fiocruz, 1996. p. 175-184.

ANTUNES, R. Os sentidos do trabalho: ensaio sobre a afirmação e negação do trabalho. São Paulo: Boitempo, 2003.

ARAÚJO, E. R. A política de tempos: elementos para uma abordagem sociológica. Revista de Ciências Sociais - Política e Trabalho, n. 34, p. 19-40, 2011.

ARAÚJO, E.; OLIVEIRA, A. de. Contornos da pesquisa/escrita/autoria e da orientação de mestrandos e doutorandos no contexto académico atual. In: OLIVEIRA, A. de; ARAÚJO, E. R.; BIANCHETTI, L. (Org.). Formação do investigador: reflexões em torno da escrita/pesquisa/autoria e orientação. Braga, Portugal: CECS/UMINHO/CED/UFSC, PT, 2014. p. 94-110. Disponível em: $<$ http://www.lasics.uminho.pt/ojs/index.php/cecs_ebooks/ issue/view/151>. Acesso em: 11 mar. 2016.

BIANCHETTI, L. O processo de Bolonha e a globalização da educação superior. Campinas: Mercado de Letras, 2015.

BONELLI, M. da G. Os desafios que a juventude e o gênero colocam para as profissões e o conhecimento científico. In: FERREIRA, C. A. et al. (Org.). Juventude e iniciação científica: políticas públicas para o ensino médio. Rio de Janeiro: EPSJV, UFRJ, 2010. p. 107-120.

BOSI, A. de P. A precarização do trabalho docente nas instituições de ensino superior no Brasil nesses últimos 25 anos. Educação \& Sociedade, Campinas, vol. 28, n. 101, p. 1503-1523, set./dez. 2007.

BOURDIEU, P. A economia das trocas simbólicas. São Paulo: Perspectiva, 1974.

. Homo academicus. 2. ed. Florianópolis: Editora da UFSC, 2011. 


\section{COORDENAÇÃO DE APERFEIÇOAMENTO DE PESSOAL DE NÍVEL} SUPERIOR - CAPES. Resultados da Avaliação da CAPES revelam que pósgraduação teve crescimento de 23\% no triênio. Brasília, DF, 2013. Disponível em: $<$ http://www.capes.gov.br/36-noticias/6689-resultados-da-avaliacaoda-capes-revelam-que-pos-graduacao-teve-crescimento-de-23-no-trienio $>$. Acesso em: 11 mar. 2017.

. Programa Jovens Talento para Ciência. Edital n. 26/2014. Brasília, DF, 2014. Disponível em: <http://www.capes.gov.br/images/stories/download/ editais/Edital_026_2014_JTC.pdf>. Acesso em: 14 mar. 2017.

\section{CONSELHO NACIONAL DE DESENVOLVIMENTO CIENTÍFICO} E TECNOLÓGICO - CNPq. Resolução Normativa nº 05 de 1993. Programa Institucional de Bolsas de Iniciação Científica - PIBIC. Disponível em: <http://www.cnpq.br/web/guest/view/-/journal_content/56_ INSTANCE_0oED/10157/81223>. Acesso em: 06 abril de 2015.

. Resolução normativa ${ }^{\circ} 017$ de 2006. Diário Oficial da União, Brasília, DF, 13 jul. 2006a. Disponível em: <http://www.cnpq.br/web/guest/ view/-/journal_content/56_INSTANCE_0oED/10157/100352\#rn17065>. Acesso em: 11 mar. 2017.

- Programa Institucional de Bolsas de Iniciação Cientifica para o Ensino Médio - PIBIC EM. Brasília, DF, 2006b. Disponível em: $<$ http://www. cnpq.br/web/guest/pibic-ensino-medio>. Acesso em: 11 mar. 2017.

\section{. Programa de Iniciação Cientifica da Olimpíada Brasileira de} Matemática das Escolas Públicas - PIC-OBMEP. [201-?a]. Disponível em: $<$ http://www.cnpq.br/web/guest/pic-obmep>. Acesso em: 14 mar. 2017.

. Programas Institucionais de Iniciação Científica e Tecnológica. [201-?b]. Disponível em: <http://www.cnpq.br/web/guest/piict $>$. Acesso em: 11 mar. 2017.

COSTA, A. O processo de formação de pesquisadores: análise do programa de iniciação científica da Universidade Federal de Santa Catarina no periodo de 1990 a 2012. 2013. 204 f. Dissertação (Mestrado em Ciência da Informação) Centro de Ciências da Educação, Programa de Pós-Graduação em Ciência da Informação, Universidade Federal de Santa Catarina, Florianópolis, 2013.

CURY, C. R. J. Graduação/pós-graduação: a busca de uma relação virtuosa. Educação \& Sociedade. Campinas, v. 25, n. 88, p. 777-793, out. 2004. Edição Especial. 
CURY, C. R. J. Quadragésimo ano do parecer CFE n. 977/65. Revista Brasileira de Educação, Rio de Janeiro, n. 30, p. 7-20, set./dez. 2005.

DALE, R. Globalização e educação: demonstrando a existência de uma -cultura educacional mundial comum - ou localizando uma - agenda globalmente estruturada para a educação-? Educação, Sociedade \& Culturas, n. 16, p. 133-169, 2001.

DEMO, P. Pesquisa: princípio científico e educativo. São Paulo: Cortez, 1990. . Educar pela pesquisa. 2. ed. Campinas: Editores Associados, 1997. . Professor e Pesquisa. . Pesquisa: fundamento docente e discente. 2009. Disponível em: $<$ https://docs.google.com/document/pub?id=1xWTfZfe mIJWrpZfD6grDHO4V6uVjOzWvm31aJ8JJlHo>. Acesso em: 11 mar. 2017.

DUARTE, N. (Org.). Crítica ao fetichismo da individualidade. 2. ed. Campinas: Autores Associados, 2012.

ESCOLA POLITÉCNICA DE SAÚDE JOAQUIM VENÂNCIO - EPSJV. Programa de Vocação Científica - PROVOC. [200-?] Disponível em: <http:// www.epsjv.fiocruz.br/index.php?Area $=$ PROVOC\&MNU=PROVOC\&Destaqu es $=1>$. Acesso em: 11 mar. 2017.

FERREIRA, C. A. O programa de vocação científica da fundação Osvaldo Cruz: fundamentos, compromissos e desafios. In: et al. (Org.). Juventude e iniciação científica: políticas públicas para o ensino médio. Rio de Janeiro: EPSJV, UFRJ, 2010. p. 27-51.

FUNDAÇÃO PERSEU ABRAMO - FPA. Acesso ao ensino superior no Brasil: a contribuição do Governo Federal no período recente. São Paulo: FPA, 2014.

GIDDENS, A. As consequências da modernidade. São Paulo: Editora UNESP, 1991.

GUIMARÃES, J. A. CNPq: História exemplar e muitos desafios. Revista Ciência Hoje. Rio de Janeiro, v. 29, n. 173, p. 52-54, jul. 2001.

INSTITUTO BRASILEIR DE GEOGRAFIA E ESTATÍSTICA - IBGE. Síntese dos indicadores sociais: uma análise das condições de vida da população brasileira: 2014. Rio de Janeiro: IBGE, 2015.

JACOBY, R. O fim da utopia: política e cultura na era da apatia. Rio de Janeiro: Record, 2001. 
LOPES, A. R. R.; ENS, R. T. Uma análise sobre formação de professores e políticas educacionais. O que dizem as teses publicadas na Capes em 2011. In: Educere, 11., Curitiba. Anais... Curitiba: Educare, 2013. p. 12.482-12.502. Disponível em: <http://educere.bruc.com.br/arquivo/pdf2013/6885>_6912. pdf $>$. Acesso em: 11 mar. 2017.

MACCARIELLO, M. do C. M. M.; NOVICKI, V.; CASTRO, E. M. N. V. de C. Articulação teoria/prática: uma ação formadora. In: CALAZANS, M. J. (Org.). Iniciação científica: construindo o pensamento crítico. São Paulo: Cortez, 2002. p. 79-115.

MACHADO, R. de C. P. Os Investimentos em Ciência e Tecnologia no Brasil. 1999. 154 f. Dissertação (Mestrado em Química Biológica). - Programa de Pós-graduação em Química, Universidade do Estado do Rio de Janeiro, Rio de Janeiro, 1999.

MARCUSCHI, L. A. Avaliação do Programa Institucional de Bolsas de Iniciação Cientifica (PIBIC) do CNPq e Propostas de Ação. Recife: UFPe, 1996.

MORAES, M. C. M. Recuo da teoria. In: (Org.). Iluminismo às avessas: produção do conhecimento e políticas de ação docente. [Rio de Janeiro]: DP\&A Editora/CNPq, 2003. p. 161-183.

. O processo de Bolonha vis a vis a globalização de um modelo de ensino superior. Perspectiva, Florianópolis, v. 24, n. 1, p.187-203, jan./jun. 2006.

. Avaliação na pós-graduação brasileira: novos paradigmas, antigas controvérsias. In: BIANCHETTI, L.; MACHADO, A. M. N. (Org.). $A$ bússola do escrever: desafios e estratégias na orientação e escrita de teses e dissertações. 3. ed. São Paulo: Cortez, 2012. p. 196-222.

NERAD, M.; HEGGELUND, M. (Ed.). Toward a Global PhD? Forces and forms in doctoral education worldwide. Seattle: University of Washington Press, 2008.

OLIVEIRA, A. de. Política cientifica no Brasil: análise da política de fomento a pesquisa do CNPq. 2003. 137 f. Dissertação (Mestrado em Educação) Centro de Ciências da Educação, Universidade Federal de Santa Catarina, Florianópolis, 2003.

PARASKEVA, J.M. et al. (Org.). Capitalismo Académico. Mangualde: Edições Pedago, 2009. 
PIRES, R. C. M. A formação inicial do professor pesquisador universitário no Programa Institucional de Bolsas de Iniciação Científica - PIBIC/CNPq e a prática profissional de seus egressos: um estudo de caso na Universidade do Estado da Bahia. 2008. 356 f. Tese (Doutorado em Educação) - Programa de PósGraduação em Educação, Faculdade de Educação, Universidade Federal do Rio Grande do Sul, Porto Alegre, 2008. Disponível em: $<$ http://capesdw.capes.gov.br/ capesdw/resumo.html?idtese $=20084442001013001 P 5>$. Acesso em: 11 mar. 2017.

RHOADES, G; SLAUGHTER, S. Academic capitalism in the new economy: challenges and choices. American Academic, v. 1, n. 1, p. 37-59, 2004. Disponível em: <http://firgoa.usc.es/drupal/files/Rhoades.qxp.pdf $>$. Acesso em: 11 de março 2016.

SANTOS, J. K. R. dos. A oportunidade de aprender sobre pesquisa na iniciação cientifica júnior de um bolsista no clube de ciências da UFPA. 2011. $171 \mathrm{f}$. Dissertação (Mestrado em Educação em Ciência e Matemáticas) - Instituto de Educação Matemática e Científica, Universidade Federal do Pará, Belém, 2011.

SANTOS, S. A. dos. Mudanças na graduação na universidade pública: a nova prática da iniciação científica. 2013. 126 f. Tese (Doutorado em Educação) Centro de Educação e Ciências Humanas, Universidade Federal de São Carlos, São Carlos, 2013.

SAVIANI, D. A expansão do ensino superior no Brasil: mudanças e continuidades. Poíesis Pedagógica, v. 8, n. 2, p. 4-17, ago./dez. 2010.

. História das ideias pedagógicas no Brasil. 4. ed. Campinas: Autores Associados, 2014.

SCHWARCZ, L. M.; STARLING, H. M. Brasil: uma biografia. São Paulo: Companhia das Letras, 2015.

SGUISSARDI, V. Regulação estatal e desafios da expansão mercantil da educação superior. Educação \& Sociedade, Campinas. v. 34, n. 124, p. 943-960, jul./set. 2013.

SILVA, E. L. da. A universidade e o ensino da pesquisa: o caso do PIBIC da UFSC. 2012. 146 f. Dissertação (Mestrado em Educação) - Centro de Ciências da Educação, Programa de Pós-Graduação em Educação, Universidade Federal de Santa Catarina, Florianópolis, 2012.

THOMPSON, E. P. Tempo, disciplina de trabalho e capitalismo industrial. In: . Costumes em comum. São Paulo: Companhia das Letras, 1998, p. 267-304. 
TREIN, E.; RODRIGUES, J. O mal-estar na academia: produtivismo científico, o fetichismo do conhecimento mercadoria. Revista Brasileira de Educação, Rio de Janeiro, vol. 16, n. 48, p. 769-819, set./dez. 2011.

UNIVERSIDADE FEDERAL DE SANTA CATARINA - UFSC. Programa Bolsista Voluntário IC. 2010. Disponível em: <http://voluntario.ufsc.br/>. Acesso em: 11 mar. 2017.

. Relatório de Atividades 2014. 2015. Disponível em: $<$ http://propesq. ufsc.br/files/2015/03/RA-2014-versao-final.pdf >.Acesso em: 11 mar. 2017.

. Pesquisadores PQ e DT CNPq/UFSC. 2017. Disponível em: http://pibic. propesq.ufsc.br/pesquisadores-dt-e-pq-cnpqufsc-2/. Acesso em: 30 mar. 2017.

VALLE, I. R.; RUSCHEL, E. A meritocracia na política educacional brasileira (1930-2000). Revista Portuguesa de Educação, v. 22, n. 1, p. 179-206, 2009.

WARDE, M. J. Sobre orientar pesquisa em tempos de pesquisa administrada. In: BIANCHETTI, L.; MACHADO, A. M. N. (Org.). A bússola do escrever: desafios e estratégias na orientação de teses e dissertações. 3 ed. São Paulo: Cortez, 2012. p. 243-262.

WEBER, S. Educação, ciência e desenvolvimento social. In: BIANCHETTI, L.; MEKSENAS, P. (Org.). A trama do conhecimento: teoria, método e escrita em ciências e pesquisa. 2 ed. Campinas: Papirus, 2011.

ZAGO, N. Do acesso à permanência no ensino superior: percursos de estudantes universitários de camadas populares. Revista Brasileira de Educação, Rio de Janeiro, v. 11, n. 32, p. 226-370, maio/ago. 2006. 


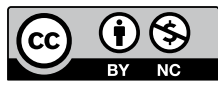

\section{Informações dos autores}

Adriano de Oliveira: Mestre e doutor em Educação pela Universidade Federal de Santa Catarina (UFSC). Coordenador Pedagógico na Rede Municipal de Ensino de Florianópolis. Membro do Grupo Traces/UFSC/CNPq. Contato: adriano.deoliveira2@gmail.com

Lucídio Bianchetti: Doutor em Educação pela Pontifícia Universidade Católica de São Paulo (PUC/SP). Estágio Pós-doutoral na Universidade do Porto, Portugal. Professor aposentado/voluntário na Universidade Federal de Santa Catarina (UFSC). Programa de Pós-Graduação em Educação da UFSC. Coordenador do Grupo Traces/UFSC/CNPq. Pesquisador 1B do CNPq. Contato: lucidio.bianchetti@pq.cnpq.br 